\title{
E-GOVERNMENT FOR SMALL LOCAL GOVERNMENT ORGANIZATIONS
}

\section{Walter Castelnovo}

Dipartimento di Scienze della Cultura, Politiche e dell'Informazione, Università dell'Insubria, via Carloni, 78 - 22100 Como (Italy), e-mail: walter.castelnovo@uninsubria.it

The Italian National Centre for Information Technology in Public Administration (CNIPA) introduced the concept of Local Alliances for Innovation (ALI) as the tool for the inclusion of small municipalities in the spread of E-Government in Italy. Based on the CNIPA's definition, the paper discusses the concept of ALI as an organizational model that can be resorted to in order to reduce the administrative fragmentation of the system of Local Government in Italy. By elaborating on the relation between the ALI model and the model of inter-municipal cooperation, the paper considers under what conditions an ALI could evolve into an Integrated System of Local Government, that is a system of Local Government Organizations strictly interoperable. Since it determines a form of virtual integration among the partners, an ISLG allows a simplification of the system of Local Government while preserving the autonomy of its members.

\section{The inclusion of small municipalities in then spread of $E$ - Government}

Starting from the year 2002, the development of E-Government in Italy has been based mostly on projects funded under the National Action Plan for EGovernment (DIT 2002), managed by the Italian National Centre for Information Technology in Public Administration (CNIPA). The National Action Plan has been based on two phases supporting innovation projects on a territorial level. The first phase started in 2002 with an announcement that funded 134 projects with 120 million euros (for an overall value of about 500 million euros).

The second phase, that is still going on, includes the funding of projects specifically devoted to the inclusion of small local government organizations (SLGOs, municipalities with less than 5000 inhabitants, that represent about the $72 \%$ of the Italian municipalities) in the spread of E-Government (CNIPA 2007a).

Please use the following format when citing this chapter:

Castelnovo, W., 2008, in IFIP International Federation for Information Processing, Volume 280; E-Government; ICT Professionalism and Competences; Service Science; Antonino Mazzeo, Roberto Bellini, Gianmario Motta; (Boston: Springer), pp. 1-10. 
The need of such funding arises from the observation that SLGOS often lack the resources necessary for handling innovation projects.

A possible solution to this problem is the sharing of resources and competencies among SLGOs, based on the model of inter-municipal cooperation (Hulst and van Montfort 2007). For this reason CNIPA provides special funding for SLGOs that define cooperation agreements for the activation of Local Alliances for Innovation (ALI), based on the model of inter-municipal cooperation. (CNIPA 2007b).

CNIPA defines ALI as alliances of SLGOs promoting inter-municipal cooperation for the management of Information Systems, technological infrastructures and ICT -based services with the aim of:

- improving the back office activities of the member municipalities through the optimization of the use of human and financial resources;

- improving the quality of the services delivered to citizens and enterprises;

- improving the processes of inter-institutional cooperation among the organizations of the Public Administration;

- achieving economies of scale in the use of ICTs

CNIPA's announcement for the funding of the ALIs specifies some of their competences, which include the definition of cooperation agreements among SLGOs for the management of services, the definition of procedural and organizational standards in order to guarantee the optimal use of the shared resources, the improvement, both quantitative and qualitative, of the services available for citizens and enterprises.

To access the funding ALIs are required to deliver at least four services to the member municipalities, according to one of the following modalities:

1. assuming the responsibility for the management of the technological platform in ASP modality and delivering assistance and training activities;

2. supporting the municipalities in their contractual relations with service providers in case of outsourcing;

3. assuming the responsibility for the management of the whole service.

Whatever the model implemented, ALIs are required to aim at the optimal use of both the instrumental and professional resources available within the municipalities adhering to the aggregation. In fact, by resorting to resources already available (especially the professional competencies) ALIs can reduce the need to acquire new resources, that would imply the increasing of the costs for the functioning of the alliance.

In case the option (3) above had been selected, the optimal use of the professional competencies already available could be achieved either by transferring them to the ALI (which could affect the functioning of the organizations they leave) or by implementing a cooperation model based on the sharing of resources belonging to different organizations. In this case the ALI should guarantee a sharing of resources among partners that could be highly heterogeneous from the organizational point of view. 
This paper will describe a process for inter-organizational integration that could be implemented by an ALI in order to evolve an aggregation of SLGOs into a system of partners strictly interoperable, also at the organizational level (which makes the sharing of professional competencies possible). More specifically, in section 2 the concept of Integrated System of Local Government (ISLG) will be introduced and the conditions enabling forms of strict inter-organizational cooperation (up to cooperability) will be considered. Finally, in section 3 a process for the implementation of an ISLG through the virtual integration of the members of an ALI will be described as a possible solution to the problem of the administrative fragmentation of the system of Local Government.

\section{Inter-municipal cooperation and cooperability}

Interoperability is a fundamental concept for inter-organizational cooperation. However, many different definitions of this concept can be found in literature, focusing on different aspects, as shown by the following definitions (AA.VV. 2007):

1. the ability of two or more systems or components to exchange and use information (IEEE 1990)

2. the ability to exchange data in a prescribed manner and the processing of such data to extract intelligible information that can be used to control/coordinate operations (NCS 1996)

3. the ability of the systems, units, or forces to provide and receive services from other systems, units, or forces and to use the services so interchanged to enable them to operate effectively together;

the conditions achieved among communications-electronics systems or items of communications-electronics equipment when information or services can be exchanged directly and satisfactorily between them and/or their users;

the capacity to integrate technology between or among different technical platforms. This form of integration is achieved through information engineering, which translates process requirements into software programs (DoD 2001).

The definitions (1) and (2) focus on systems inter-connectivity and components inter-changeability (Stegwee and Rukanova 2003), whereas the definition (3) adds to the concept of interoperability a different aspect concerning the ability of the partners of the cooperation to operate effectively together. Actually, although systems inter-connectivity and components inter-changeability can be considered as necessary conditions for inter-organizational cooperation, they cannot be considered as sufficient conditions.

Generally, inter-organizational cooperation does not concern simply information exchanges among different organizations; rather it concerns the capability of different organizations to operate together in order to achieve a common goal. In this sense, to enable an inter-organizational cooperation some form of organiza- 
tional compatibility is needed, besides systems interoperability. This aspect of inter-organizational cooperation has been considered within the ATHENA project (ATHENA 2007) where an interoperability framework has been defined based on four layers of interoperability:

- Applications layer, data and communication components

- Knowledge layer: organizational roles, skills and competencies of employees and knowledge assets

- Business layer: business environment and business processes

- Semantic layer: support mutual understanding on all layers

With reference to E-Government, the multi-dimensionality of interoperability has been underlined also within the European Interoperability Framework for PanEuropean E-Government (EIF) that aims at determining the conditions to make public administrations of EU countries interoperable. The framework considers three aspects of interoperability: technical interoperability, semantic interoperability and organisational interoperability (IDABC 2004).

Both ATHENA and the EIF define interoperability in a way that goes beyond the compatibility of systems and applications, recognizing the need to account for a broader concept of organization compatibility.

In a different context, concerning the definition of interoperability as an essential element for the effective formation of Joint, Allied or Coalition task forces, (Clark and Jones 1999) describes an organizational interoperability maturity model in which the organizational elements allowing a full compatibility of the partners are defined by four attributes characterizing inter-organizational cooperation. The attributes are Preparedness, Understanding, Command Style and Ethos. On the base of the different values such attributes can take, different levels of cooperability (Gompert and Nerlich 2002) can be defined as in the table 1 below:

Table 1. Organizational Maturity Model

\begin{tabular}{|c|c|c|c|c|}
\hline $\begin{array}{l}\text { Levels of coo- } \\
\text { perability }\end{array}$ & Preparedness & Understanding & Command style & Ethos \\
\hline Unified & $\begin{array}{l}\text { Complete, normal } \\
\text { day-to-day working }\end{array}$ & Shared & Homogeneous & Uniform \\
\hline Combined & $\begin{array}{l}\text { Detailed doctrine and } \\
\text { experience in using it }\end{array}$ & $\begin{array}{l}\text { Shared communica- } \\
\text { tions and shared } \\
\text { knowledge }\end{array}$ & $\begin{array}{l}\text { One chain of } \\
\text { command and in- } \\
\text { teraction with } \\
\text { home organiza- } \\
\text { tions }\end{array}$ & $\begin{array}{l}\text { Shared ethos but } \\
\text { with influence } \\
\text { from home or- } \\
\text { ganizations }\end{array}$ \\
\hline Collaborative & $\begin{array}{l}\text { General doctrine in } \\
\text { place and some expe- } \\
\text { rience }\end{array}$ & $\begin{array}{l}\text { Shared communica- } \\
\text { tions and shared } \\
\text { knowledge about } \\
\text { specific topics }\end{array}$ & $\begin{array}{l}\text {-Separate reporting } \\
\text { lines of responsi- } \\
\text { bility overlaid with } \\
\text { a single command } \\
\text { chain }\end{array}$ & $\begin{array}{l}\text { Shared purpose; } \\
\text { goals, value sys- } \\
\text { htem significantly } \\
\text { influenced by } \\
\text { home organiza- } \\
\text { tions }\end{array}$ \\
\hline
\end{tabular}




\begin{tabular}{llll}
\hline Ad hoc & General guidelines & $\begin{array}{l}\text { Electronic commu- Separate reporting Shared purpose } \\
\text { nications and lines of responsi- } \\
\text { shared information bility }\end{array}$ \\
Independent $\quad$ No preparedness & $\begin{array}{l}\text { Communication via No interaction } \\
\text { phone, etc. }\end{array}$ & $\begin{array}{l}\text { Limited shared } \\
\text { purpose }\end{array}$ \\
\hline
\end{tabular}

The organizational interoperability maturity model described in (Clark, Jones 1999) exclusively considers the non-technical aspects of interoperability (Stewart, et al. 2004). As such, the organizational interoperability maturity model can be integrated with a description of the levels of Information Systems interoperability, for instance the one introduced in (AA.VV. 1998).

The correspondence among the levels of cooperability and the levels of Information Systems interoperability can be summarized as in table 2:

Table 2. Relation between the Organizational Maturity Model and the Levels of Information Systems Interoperability model.

Levels of coopera- Levels of Information Systems Interoperability (LISI)

bility

Unified

Enterprise (Universal): Interactive manipulation; Shared Data and applications

Combined

Domain (Integrated): Shared data; "Separate" applications

Collaborative

Functional (Distributed): Minimal common Functions; Separate data and applications

Ad hoc

Connected (Peer-to-Peer): Electronic connection; Separate data and applications

Independent

Isolated (Manual): Non-connected, use of manual gateways (diskettes, etc.)

The correspondences in Table 2 point out how the achievement of a certain level of cooperability (i.e. organizational interoperability) requires at least the achievement of the corresponding level of integration of the information systems; yet, without this implying that a close integration at the technological level can also determine a close integration at the organizational level.

The conditions characterizing the different levels of cooperability combined with the conditions characterizing the corresponding levels of information systems interoperability can be used to define the properties of a cooperation environment that can be implemented to support an inter-municipal cooperation. Depending on their more or less restrictive character, the conditions defining the cooperation environment can lead to more or less strict forms of partnership among SLGOs, up to the definition of an Integrated System of Local Government (ISLG), as described in (Castelnovo and Simonetta 2005, 2006).

An Integrated System of Local Government is made up of SLGOs that, on the basis of a preliminary sharing of interests (e.g. increasing both the efficiency and effectiveness of the administration, realization of economies of scale and of scope, 
management of technological and organizational innovation, etc.), jointly define systematic forms of cooperation based on the appropriate cooperation environment.

The conditions defining the cooperation environment concern both technological, operative, organizational and regulative conditions, as summarized in the table 3 below:

Table 3. Conditions for interoperability

\begin{tabular}{ll}
\hline $\begin{array}{l}\text { conditions concerning the sharing of infrastructures (virtual or physical) } \\
\text { for the network communication }\end{array}$ \\
$\begin{array}{l}\text { Technological intero- } \\
\text { perability }\end{array}$ \\
$\begin{array}{l}\text { conditions defining the standards for communication and for systems } \\
\text { interoperability } \\
\text { conditions for the definition and the sharing of security policies for the } \\
\text { access to information resources and for their use } \\
\text { conditions concerning the standardization of the processes }\end{array}$ \\
conditions concerning the definition of the operational standards \\
Operational interope- \\
rability \\
tionditions for the sharing of the resources (physical resources, informa- \\
conditions for the monitoring of the activity of the members of the as- \\
sociation \\
conditions concerning the creation of shared managerial styles \\
Organizational intero-
\end{tabular}

Within an ISLG, sharing a cooperative environment makes the partner strongly interoperable, not only on the technological level, but on the organizational level as well, up to the achievement of levels of full cooperability among the partners. In this sense, the setting up of an ISLG can be considered as the result of a process of joint technological and organizational innovation.

\section{From Local Alliances for Innovation to Integrated Systems of Local Government}

Although an integrated system is sometimes considered to be more tightly coupled than a system of interoperable components, it is useful to stress that the distinction 
between systems integration and systems interoperability (up to cooperability) is a question of perspective. What is seen from outside as the result of the integration of different organizations, from the point of view of the partners can simply be a system of independent and strictly cooperable organizations.

ISLG members are not, strictly speaking, integrated in the system, as that would imply an overcoming of their autonomy and individuality; actually, the implementation of an ISLG simply amounts to the sharing of the appropriate technological and organizational platform, which makes interorganizational cooperation easier. In this sense, the activation of an ISLG could also be considered as the result of the transformation of an aggregation of SLGOs, that could have been set up in order to achieve immediate results, in a long-term, well-structured cooperation.

The integration among the partners within an ISLG is only virtual and it is determined by the strengthening of the conditions of interoperability (up to cooperability) rather than by a real organizational integration. This has some particularly important consequences:

- each member of the ISLG keeps its autonomy, though it agrees to coordinate its activity with that of its partners and to systematically share resources (of various sorts) with them;

- as the integration is exclusively determined by the adoption of a shared cooperation environment, the activation of an ISLG:

- could simply be the result of the transformation of an aggregation of SLGOs in a stable and strategic cooperation;

- does not necessarily require the definition of new levels of government (as it happens in the case of institutionalized forms of integration.

Thanks to these characteristics, an ISLG can represent a solution to the need to overcome administrative fragmentation, in order to achieve the rationalization, the simplification and the reduction of the costs of the system of Local Government.

As defined by CNIPA, ALIs are simply aggregations of municipalities that define cooperation agreements for the implementation of various forms of intermunicipal cooperation. In broad terms, inter-municipal cooperation may be defined as an arrangement between two or more government organizations for accomplishing common goals, providing a service, or solving a mutual problem (Council of Europe 2007). In this sense, a municipality could resort to intermunicipal cooperation also for opportunistic reasons; for instance, taking advantage of favourable conditions (such as funding exclusively devoted to aggregations of municipalities) or solving an immediate problem. In case of an opportunistic cooperation, the same municipality can join different aggregations, even without territorial contiguity constraints; moreover, the cooperation could be episodic since it is not based on a long tem commitment to the partners.

However, in order to achieve the rationalization, the simplification and the reduction of the costs of the system of Local Government through inter-municipal cooperation, the aggregations that set up must necessarily be stable in time and re- 
spond to a strategic commitment of the partners towards the cooperation. By defining a cooperation agreement for the activation of an ALI, the members of an aggregation of municipality make such a commitment. However, the adhesion to an ALI by itself does not guarantee the stability of the cooperation. Actually, such a result could be achieved more easily through the sharing of a cooperative environment. In fact, sharing a cooperation environment means to adhere to the conditions of technical interoperability and, above all, to the cooperability constraints that define it. This can mitigate the opportunistic behaviour of the partners (which is one of the main causes of aggregation instability) and, therefore, can force the stability of an aggregation that turns into an ISLG.

From this point of view, an ALI can evolve into an ISLG as a result of an organizational innovation process that aims at the strengthening of the conditions for the cooperation. Such a process should be focused on the development and the subsequent adoption of a shared cooperation environment, mostly based on the non technical aspects of interoperability, as those considered in section 2 above.

As it has been defined, an ISLG simply determines a virtual integration among the partners and, as such, it does not depend on the geographical collocation of its members. However, since an ALI is defined on a territorial basis, an ALI that evolves into an ISLG keeps its territorial basis. This allows an ISLG to provide answers to the specific needs of a local community, both by delivering particular services required by the socio-economic local environment and by preserving the peculiar characteristics of the local system of Government.

The territorial basis of an ISLG does not preclude the possibility that, through the coordination of a higher institutional level authority, different ISLGs can be made cooperable. This could determine a further process of (virtual) integration on a larger territorial scale, allowing the systematic cooperation among different ISLGs defined at the local level.

From this point of view, it is possible to define a process for the reduction of the administrative fragmentation at the Local Government level that, starting from the activation of an ALI, could lead to a system of Local Government (virtually) integrated, for instance, at Regional level. Such a process could be based on the strengthening of the conditions for the inter-institutional cooperation among municipalities at the lowest level, and among ISLGs at a higher level.

This integration process, that can be considered as a process for the simplification of the system of Local Government, can be described also in terms of the maturity model for inter-municipal cooperation summarized in table 4:

Table 4. Maturity model for inter-municipal cooperation

\begin{tabular}{ll}
\hline $\begin{array}{l}\text { Administrative frag- } \\
\text { mentation }\end{array}$ & $\begin{array}{l}\text { Presence of completely independent organizations that have not de- } \\
\text { fined any form of cooperation. }\end{array}$ \\
\hline Episodic cooperations & $\begin{array}{l}\text { Presence of different forms of inter-municipal cooperation, due to the } \\
\text { necessity of taking advantage of favourable situations (such as funding } \\
\text { exclusively devoted to aggregations of municipalities). The cooperation } \\
\text { is opportunistic; the same municipality can join different aggregations, }\end{array}$ \\
\hline
\end{tabular}


even without territorial contiguity constraints.

Stable aggregations Setting up of stable and multi-functional aggregations, which imple(ALI) ment long-term sharing of different kinds of resources. The cooperation is no more opportunistic: joining an aggregation is a strategic decision.

Integrated Systems of Stable aggregations involved in an integration process (in terms of coLocal Government operability conditions), setting up an integrated system. The intermunicipal cooperation turns into systematic sharing of information, technological and human resources.

Cooperation among The cooperation is not anymore restrained to a territorial area; differISLGs ent interoperable ISLGs can cooperate within a wider context defined by regional bounds.

\section{Conclusions}

Inter-municipal cooperation represents a well-known organizational model SLGOs can resort to in order to share resources that they individually lack. By assuming the Local Alliances for Innovation as the model for the inclusion of small municipalities in the spread of E-Government, the Italian National Centre for Information Technology in Public Administration acknowledges inter-municipal cooperation as a tool for the rationalization, the simplification and the reduction of the costs of the system of Local Government.

In the paper the achievement of these objectives has been related to the implementation of systematic forms of cooperation among municipalities belonging to stable aggregations. The stability of the aggregations can be forced by the adoption of a cooperation environment that, depending on the conditions characterizing it, can determine a form of virtual integration among the partners.

Such a virtual integration, achieved through the strengthening of the interoperability conditions (up to cooperability) allows a reduction of the administrative fragmentation, even in those contexts in which the simplification of the system of Local Government cannot be achieved by means of a forced merger of municipalities.

\section{References}

AA.VV. (2007), Current Perspectives on Interoperability, Technical Report, CMU/SEI-2004TR-009 - ESC-TR-2004-009, Carnegie Mellon Software Engineering Institute.

AA.VV. (1998), Levels of Information Systems Interoperability (LISI), C4ISR - Architecture Working Group"; online: www.dod.mil/nii/org/cio/i3/AWG_Digital_Library/pdfdocs/lisi.pdf. ATHENA (2007), Advanced Technologies for interoperability of Heterogeneous Enterprise Networks and their Applications - an Integrated Project sponsored by the European Commission - www.athena-ip.org. 
Castelnovo, W., Simonetta, M. (2005), "Organizing E-Government for Small Local Government Organizations", Proceedings of the 5th European Conference on E-Government, Antwerpen.

Castelnovo, W. and Simonetta, M. (2006), "Networks of SLGOs: from systems interoperability to organizational cooperability", Proceedings of The 6th European Conference on EGovernment, Marburg.

Clark, T., Jones, R. (1999), “Organisational Interoperability Maturity Model for C2”, Poceedings of the Command and Control Research and Tecnology Symposium, Newport.

CNIPA (2007a), Linee di azione (II fase); online: http://www.cnipa.gov.it

CNIPA (2007b), Avviso per il cofinanziamento di progetti proposti dalle Alleanze Locali per l'Innovazione (ALI); online: http://www.cnipa.gov.it

Council of Europe (2007), Draft Report on Inter-Municipal Cooperation, Directorate General I Legal Affairs, Directorate of Cooperation for Local and Regional Democracy, Council of Europe, 2007.

DIT (2002), "Avviso per la selezione di progetti proposti dalle Regioni e dagli Enti locali per l'attuazione dell'e-Government", Gazzetta Ufficiale, n. 78, 3 April 2002.

DoD (2001), Department of Defense Dictionary of Military and Associated Terms, Operational Plans and Joint Force Development Directorate, Washington DC., online: http://www.dtic.mil/doctrine/jel/new_pubs/jp1_02.pdf.

Gompert, D. C., Nerlich, U. (2002), Shoulder to Shoulder - The Road to U.S. European Military Cooperability. A German American Analysis, RAND Corporation, online:http://www.rand.org/.

Hulst, R. and van Montfort, A.. (2007), Inter-municipal Cooperation in Europe, Springer, Dordrecht.

IDABC (2004), European Interoperability Framework for Pan-European E-Government Services. Version 1.0; online: europa.eu/idabc/.

IEEE (1990), IEEE Standard Glossary of Software Engineering Terminology (IEEE Std 610.121990), The Institute of Electrical and Electronics Engineers, New York.

NCS (1996), Telecommunications: Glossary of Telecommunication Terms (Federal Standard 1037C), National Communications System; online: http://www.its.bldrdoc.gov/fs-1037/.

Stegwee, R. A., Rukanova, B.D. (2003), Identification of different types of standards for domain-specific interoperability, Standard Making: A Critical Research Frontier for Information Systems, MISQ Special Issue Workshop.

Stewart, K., Clarke, H., Goillau, P., Verrall, N., Widdowson, M. (2004), Non - technical Interoperability in Multinational Forces, Command and Control Research and Technology Symposium - The Power of Information Age Concepts and Technologies, QinetiQ Ltd. 